\title{
Creativity as a mediator between personal accomplishment and task performance: A multigroup analysis based on gender during the COVID-19 pandemic
}

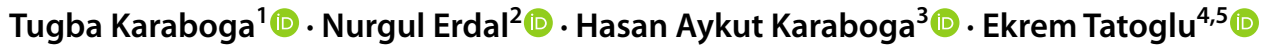 \\ Accepted: 11 November 2021 \\ (c) The Author(s), under exclusive licence to Springer Science+Business Media, LLC, part of Springer Nature 2021
}

\begin{abstract}
The current pandemic of coronavirus disease 2019 (COVID-19) is not only a health crisis but also a social crisis that affects all people and all parts of society from various perspectives. Effective management of the emotional and psychosocial effects of the pandemic is a critical issue for individuals and societies. In this study, the mediating role of creativity on the relationship between personal accomplishment and task performance was examined during the COVID-19 pandemic. In addition, a gender-based comparison analysis was performed to extend the analysis results. Survey-based research data were collected from 322 people working in different sectors. Partial least squares-based structural equation modeling (PLS-SEM) was used to analyze research data. The results indicated that personal accomplishment had a significant positive effect on both creativity and task performance. Also, it was found that creativity had a mediating role in the relationship between personal accomplishment and task performance. Lastly, the gender-based multigroup analysis (MGA) revealed a significant difference between male and female participants with respect to the relationship between personal accomplishment and task performance, between creativity and task performance, between personal accomplishment and task performance through creativity.
\end{abstract}

Keywords COVID-19 $\cdot$ Personal accomplishment $\cdot$ Creativity $\cdot$ Task performance $\cdot$ Self-efficacy theory

\section{Introduction}

Tugba Karaboga

hidirlar@yildiz.edu.tr; tugba.karaboga14@gmail.com

Nurgul Erdal

nurgul.erdal@istanbul.edu.tr

Hasan Aykut Karaboga

h.aykut.karaboga@amasya.edu.tr

Ekrem Tatoglu

tatoglu.e@gust.edu.kw; ekrem.tatoglu@ihu.edu.tr

1 Faculty of Economics and Administrative Sciences, Yildiz Technical University, 34220, Esenler, Istanbul, Turkey

2 Cerrahpasa Faculty of Medicine, Istanbul University, 34098 Istanbul, Turkey

3 Faculty of Education, Amasya University, 05100, Merkez, Amasya, Turkey

4 College of Business Administration, Gulf University for Science \& Technology, Block 5, Building 1, Mubarak Al-Abdullah Area, West Mishref, Kuwait

5 School of Business, Ibn Haldun University, Basak Mah., Ordu Cad., F-05 Blok, No: 3, Basaksehir, 34480 Istanbul, Turkey
The novel coronavirus disease 2019 (COVID-19) has been a pandemic that threatens all humanity and reveals economic, political, socio-cultural, and technological changes in the world. The uncertainty brought about by the pandemic has caused great fear in people who have tried to maintain their jobs and daily routines while trying to protect their health at the same time (Swaminathan \& Mishra, 2020). Private sector organizations, public institutions, healthcare organizations, and governments worldwide have fought together to slow down the speed of the pandemic and mitigate its adverse effects (Gates, 2020). However, with a "new normal" life order around the world, the increasing number of COVID-19 patients and deaths has once again started to deeply affect people's well-being, quality of life, professional careers, business achievements, and personal achievements.

Since 2020, people have faced many adverse situations due to the pandemic and its ensuing strict rules. Practices such as quarantines, curfews, social distancing, staying at home processes, and working from home, have created a new lifestyle, and these restrictions have caused 
psychological pressure on people. Effective management of the emotional and psychosocial effects of the uncertainty and crisis that emerge during pandemic periods is a severe issue for individuals and societies. In order to manage the pandemic crisis in a healthy way, it is crucial to obtain correct information, pay attention to hygiene rules, reduce anxiety and fear, establish a daily routine, improve oneself individually, achieve enjoyable occupations, and make behavioral changes that increase personal success by improving creativity characteristics. Creativity is related to producing new and valuable ideas to overcome a problem (Amabile \& Pratt, 2016). Creativity is vital for developing rapid solutions to problems under the pressure of the high uncertainty and resource scarcity of the COVID-19 pandemic (Cohen \& Cromwell, 2020). Personal accomplishment is related to people's feelings of competence and success orientation in their work (Maslach et al., 1997). High stress levels and anxiety affect employee creativity and feelings of personal accomplishment (George \& Zhou, 2002; Martínez-Monteagudo et al., 2019). In a time of crisis during the pandemic, creative employees and feelings of accomplishment become more valuable to support performance outcomes and to create an energetic working environment (Mardanov, 2020; Tang et al., 2021; Tu et al., 2021) When the feelings of personal accomplishment increase, an individuals' motivation, productivity, creativity, and ability to cope with problems also increase (Baysal, 1995). Creative employees can develop novel ideas related to products, services, and work processes that benefit organizations (Amabile \& Conti, 1999). The outcomes of creativity can support employee performance from various perspectives. Creative workers overcome problems such as burnout and stress and can contribute to task performance by working at higher productivity levels (Eschleman et al., 2014). Task performance is related to succeeding at the formal job requirements defined in work procedures (Yu \& Frenkel, 2013). When employees' personal accomplishment and individual creativity levels are high, their task performance is also expected to be high.

Although the relationships between creativity-task performance (Eschleman et al., 2014; Taboli \& Zaerizadeh, 2016), creativity-personal accomplishment (Ghonsooly, 2012; Hsu et al., 2011), and personal accomplishment-task performance (Fogarty et al., 2000; Wright \& Bonett, 1997) were studied in previous literature, these three variables were not considered together. Therefore, this study aims to investigate the relationship between the feeling of personal accomplishment, individual creativity, and task performance during the COVID-19 pandemic. It contributes to the literature by examining the mediating role of creativity on the linkage between personal accomplishment and task performance. Also, gender-based group comparisons to understand the differences between male and female participants using the literature-driven model and proposed relationships is another valuable contribution to the existing knowledge.

\section{Theoretical Framework and Hypothesis Development}

The social cognitive theory of Bandura (2001) points out that people are motivated by judgments about their ability to perform certain tasks and performance expectations of their actions. Individuals' judgments of capabilities and performance expectations are affected by their self-efficacy, one of the main elements of social cognitive theory. Self-efficacy is a cognitive factor that activates an individual's performance. Individuals with high self-efficacy levels set challenging goals for themselves, are determined to continue their duties, and can develop various ways to cope with obstacles (Hsu et al., 2011). Bandura (1997) bases self-efficacy acquisition on four sources: mastery experience (experiences gained from individual achievements), vicarious experience (taking position according to others' performance), verbal persuasion (incentives and advice that affect an individual's success in a job), and physiological states (emotional judgments of an individual about completing specific tasks).

Depending on self-efficacy theory (Bandura, 1997), this study recommended two influential variables: personal accomplishment and task performance and examined the mediating role of employee creativity on the relationship between personal accomplishment and task performance under the moderator effect of gender.

\section{Personal Accomplishment and its Relationship to Creativity}

Personal accomplishment is defined as a "feeling of competence and successful achievement in one's work with people" (Maslach \& Jackson, 1981:101). According to Bandura's efficacy theory (1986), personal accomplishment is related to the experience of mastery which constitutes the most critical source of self-efficacy. If people perform a job, the feeling of accomplishment gives them confidence and assures them that they can successfully do similar tasks. In contrast, if people fail at a job, their self-efficacy and feeling of accomplishment weaken (Bandura, 1997).

Creativity can be defined as a cognitive ability that emerges as a novel or skill-based product, includes newly emerged problem-solving processes, and uses the intelligence elements of a person for production in an original way (Aslan, 2016). According to Bandura (1997), all individuals can achieve creative results according to their expertise, creative thinking skills, and task motivation. The social cognitive theory emphasizes that creative self-efficacy encourages individuals to participate in creative processes and enables 
them to believe that they can perform these processes successfully (Bandura, 2001). In the era we live in, creative individuals use novel information technologies effectively, have creative thinking, and exhibit creative skills while solving challenging problems they face in their work or daily lives. The creativity of employees is an essential asset for organizations to achieve their performance objectives. Individual creativity develops new and practical methods for solving workplace problems by providing concrete and valuable outcomes for organizations (Zhou et al., 2012).

When the feeling of personal accomplishment increases, an individuals' motivation, productivity, creativity, and ability to cope with problems also increase (Baysal, 1995). Feelings of personal success related to people's jobs help individuals create innovative ideas at their work tasks (Hsu et al., 2011). In the literature, some researchers found a positive link between personal accomplishment and individual creativity (Ghonsooly, 2012; Landeche, 2009). In line with the literature, personal accomplishment supports people's feelings of efficacy by increasing perseverance to overcome obstacles by working toward creative outcomes (Bang \& Reio Jr, 2016). Thus, employees with a high level of personal achievement in their field of expertise will be confident that they will be more creative even at high difficulty levels. Drawing on the given arguments, we propose a positive relationship between personal accomplishment and individual creativity.

\section{H1: Personal accomplishment is positively related to creativity.}

\section{Creativity and Task Performance Relationship}

Task performance is related to the fulfillment of activities within job descriptions, which are related to the mastery and professional aspects of a job. In other words, task performance is related to the fulfillment of basic roles and responsibilities that are necessary for performing a job (Jawahar \& Carr, 2007). For task performance, technical knowledge and skills are required to accomplish a task (Miller et al., 1999). Employees' job-related technical knowledge and skills are essential for organizations since they indirectly contribute to the efficiency, effectiveness, and performance goals of the enterprises (Jawahar \& Carr, 2007).

Creativity is an essential prerequisite for sustaining competitiveness in today's business, where uncertainty and risk increase (Pattnaik \& Sahoo, 2021). Creative workers are more likely to outperform and beat the competition in generating new ideas (Amabile \& Pratt, 2016). According to Bandura (1997), self-efficacy is essential for individual creativity, which affects developing new ideas and producing novel solutions for problems they face in the work environment (Hon \& Lui, 2016). If creative employees are allowed to participate in decision-making processes, they can increase company performance through their task performance. In this way, creative employees can develop novel ideas related to products, services, and work processes beneficial for organizations (Amabile \& Conti, 1999). Modern organizations value creativity as a path to enhanced performance by making organizations rapidly adapt to changing technological and environmental conditions (Choi et al., 2009). Some of the studies also demonstrated that creativity is related to employee performance from various perspectives. For example, Eschleman et al. (2014), Taboli and Zaerizadeh (2016), and Janssen and Giebels (2013) found a positive relationship between employee creativity and performance-related outcomes of employees. Depending on the given arguments, we propose a positive relationship between creativity and task performance, which is stated in the following hypothesis.

H2: Creativity is positively related to task performance.

\section{Personal Accomplishment and Task Performance Relationship}

Task performance is fed by the knowledge, skills, and competence of the employees and contributes to the employees' fulfillment of their job-related responsibilities (Miller et al., 1999). Task performance, which can also be described as the efficiency level of the employees, is also closely related to the personality traits and self-efficacy of the employees (Stajkovic \& Luthans, 1998). Vinchur et al. (1998) found a positive relationship between people with high achievement need and task performance. Also, it was shown by Bell and Kozlowski (2002) that people with high self-efficacy also have high task performance.

Personal accomplishment strengthens feelings of competence, self-confidence, and success motivations. Bandura (1989) associated the sense of personal accomplishment with self-efficacy and expressed self-efficacy as the ability to control the events that affect people's lives. Some studies indicated self-efficacy as a strong predictor of task performance (Wright \& Bonett, 1997). Similarly, studies investigating burnout and its relationship to employee performance also showed a positive link between enhanced personal accomplishment and job performance (Fogarty et al., 2000; Wright \& Bonett, 1997). Accordingly, we propose a positive relationship between personal accomplishment and task performance, which leads to the following hypothesis.

H3: Personal accomplishment is positively related to task performance. 


\section{The Mediating Role of Creativity}

The research model and theoretical discussion support a relationship between personal accomplishment and creativity on the one hand and creativity and task performance on the other. This made us consider that creativity could have a mediating effect between personal success and task performance (see Fig. 1.).

Previous literature states that personal accomplishment is related to mastery experience of self-efficacy (Bandura, 1997). Self-efficacy beliefs of people with a high sense of personal accomplishment also encourage them to be more creative (Bang \& Reio Jr, 2016). Personal accomplishment makes people perform their tasks successfully and achieve their goals effectively (Bandura, 1997). Personal accomplishment is also closely related to individual creativity. Halbesleben and Buckley (2004) stated that people who experience a decrease in personal accomplishment also decrease their creativity and problem-solving abilities. As the sense of personal accomplishment increases, employees feel more motivated, focus better on their work, get along better with their colleagues, and become more productive and creative (Baysal, 1995). In an intensely competitive environment of the new world order, the growth of businesses, the production of innovative products and services, and the development of innovative marketing activities are closely related to the creativity levels of employees (Mumford et al., 2002). As employee creativity increases, the innovative ideas and smart problem solutions they produce are expected to contribute to their efficiency levels and performance. When individuals are allowed to be creative and think differently in the business environment, they both contribute to the performance of the business and show better task performance by working at a higher efficiency level (Eschleman et al., 2014). As an intrinsic motivation factor, creativity activates the curiosity of individuals, encourages the need to explore, and enhances task performance by unlocking their true potential (Pattnaik \& Sahoo, 2021; Ryan \& Deci, 2000). Based on this discussion and previous empirical evidence, the following hypothesis is assumed.

H4: Employee creativity mediates the relationship between personal accomplishment and task performance.

\section{The Impact of Gender on the Proposed Relationships}

According to social cognitive theory, there are personal and interpersonal factors that affect people's daily lives, emotions, thoughts, and behaviors (Bandura, 1989). Gender is one of the personal factors that affect people's daily lives and have various social effects. The social role theory states that the differences in the roles of men and women in social life are also reflected in people's behaviors and ways of doing business in business life (Eagly et al., 1995). When this theory is applied to work, external rewards such as wages, promotion, the idea of being successful, and high performance become more important for men. In contrast, social rewards such as being socially accepted by their friends, establishing good relations with others, and adapting to the environment become more important for women (Kacmar et al., 2011; Ouyang et al., 2015). Therefore, agentic behaviors of men and communal behaviors of women are expected to enable men and women to achieve different outputs on issues such as creativity, personal accomplishment, and task performance.

In the extant literature, some researchers indicate that gender impacts job performance (Burleson \& Samter, 1992; King et al., 2010; Nasir et al., 2011) and personal accomplishment levels of people (Jamaludin \& You, 2019). Compared to women, the sense of personal accomplishment and job performance is more prominent in men (Kacmar

Fig. 1 Conceptual framework

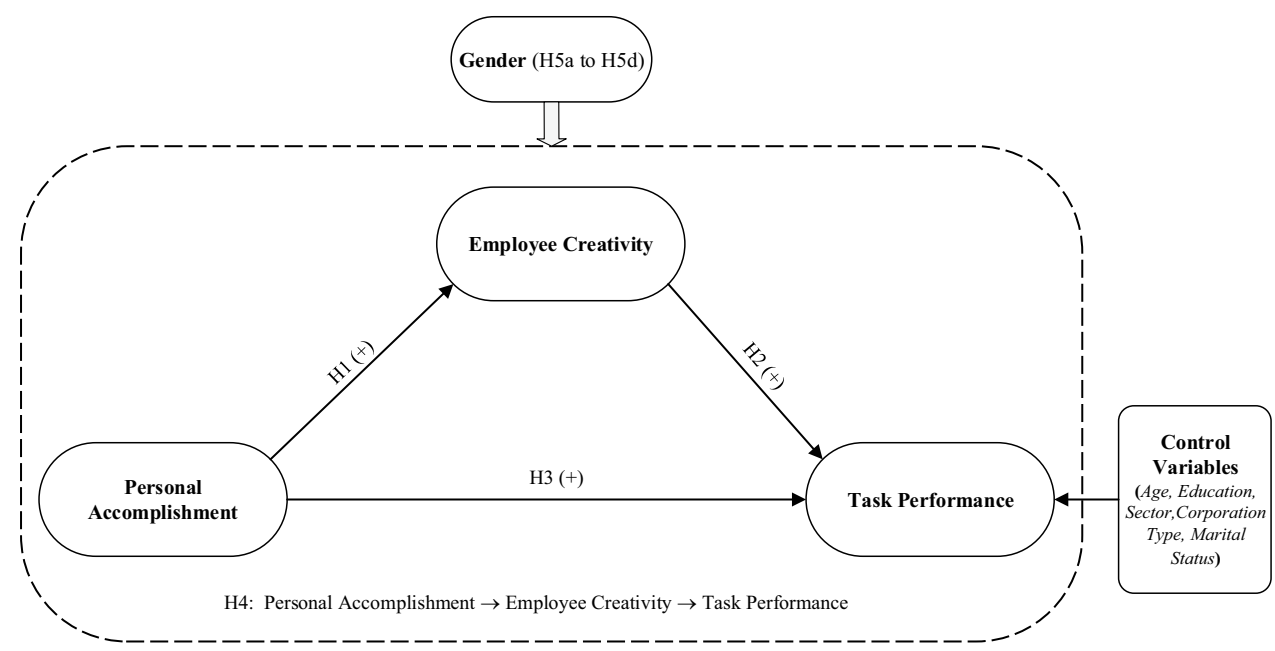


et al., 2011). Therefore, the relationship between personal accomplishment and task performance is expected to be different for men and women. On the other hand, although the effect of gender difference on creativity has not been fully clarified (Stoltzfus et al., 2011), it is known that women are more task-oriented and try to do the best work, while men are more risk-taking, curious to try new things and open to differences (Baer \& Kaufman, 2008). Thus, men are generally expected to become more creative than women (Smith et al., 2016). In this context, the relationship between personal accomplishment and creativity and the relationship between creativity and task performance are expected to be at different levels between male and female groups. In addition, since gender is known to have a different effect on the three main variables in the research model, gender is expected to have a differentiating effect on the mediator effect of creativity between personal accomplishment and task performance. Based on the previous empirical support, we developed the following multi-part hypothesis.

H5a: Males and females vary significantly in terms of the relationship between personal accomplishment and creativity.

H5b: Males and females vary significantly in terms of the relationship between creativity and task performance. H5c: Males and females vary significantly in terms of the relationship between personal accomplishment and task performance.

H5d: Males and females vary significantly in terms of the relationship between personal accomplishment and task performance through creativity.

\section{Methods}

\section{Participants}

Data for this study were collected through an online survey between June 2020 and October 2020. A total of 345 people working in various sectors were contacted through online platforms for our research. After the elimination of 23 invalid responses, we had 322 valid responses (133 (41.3\%) men and 189 (58.7\%) women), including 213 public sector workers, 63 private sector workers, and 46 self-employed workers. Table 1 shows the demographic profiles of the respondents.

Before starting data analysis, we calculated the minimum sample size via different methods. In partial least squaresbased structural equation modeling (PLS-SEM), Chin (2010) proposed that a sample size between 100 and 200 is adequate. Based on statistical power, Cohen's power statistics recommended 45 samples for statistical power of $80 \%$ and a minimum $R^{2}$ value of 0.25 with a $5 \%$ significance level
Table 1 Demographic characteristics of respondents

\begin{tabular}{|c|c|c|c|}
\hline & & Frequency & Percent \\
\hline \multirow[t]{3}{*}{ Corporation type } & Public corporation & 213 & 66.1 \\
\hline & Private corporation & 63 & 19.6 \\
\hline & Self-employed & 46 & 14.3 \\
\hline \multirow[t]{6}{*}{ Sector } & Education & 38 & 11.8 \\
\hline & Finance & 21 & 6.5 \\
\hline & Health & 137 & 42.6 \\
\hline & Textile & 19 & 5.9 \\
\hline & Food and beverage & 36 & 11.2 \\
\hline & Other & 71 & 22.0 \\
\hline \multirow[t]{6}{*}{ Age (years) } & Less than 21 & 6 & 1.9 \\
\hline & 21 and 30 & 46 & 14.3 \\
\hline & 31 and 40 & 85 & 26.4 \\
\hline & 41 and 50 & 118 & 36.6 \\
\hline & 51 and 60 & 57 & 17.7 \\
\hline & More than 60 & 10 & 3.1 \\
\hline \multirow[t]{2}{*}{ Sex } & Male & 133 & 41.3 \\
\hline & Female & 189 & 58.7 \\
\hline \multirow[t]{2}{*}{ Marital status } & Single & 92 & 28.6 \\
\hline & Married & 230 & 71.4 \\
\hline \multirow[t]{7}{*}{ Education } & Primary school & 10 & 3.1 \\
\hline & High school & 55 & 10.0 \\
\hline & College & 32 & 9.9 \\
\hline & Undergraduate & 135 & 41.9 \\
\hline & Graduate & 77 & 23.9 \\
\hline & Doctorate & 13 & 4.0 \\
\hline & Total & 322 & 100.0 \\
\hline
\end{tabular}

with five predictors (Hair et al., 2017). The ten times rule gave us the required sample size of 100 samples (Aggarwal \& Kapoor, 2020). So, in this study, 322 respondents were adequate for evaluating proposed relationships.

\section{Measures}

All measures used in this study were adapted from previously used scales with sufficient reliability and validity values. All scale items were measured on a 5-point Likert scale ( $1=$ strongly disagree, $5=$ strongly agree $)$.

Personal accomplishment (PER-ACC) was measured by adopting the sub-scale of the Maslach Burnout Index developed by Maslach and Jackson (1981). We used the Turkish version of this scale which was adapted by Ergin (1992). The personal accomplishment construct measure includes eight items. A higher score on the scale designates higher personal accomplishment levels.

Employee creativity (EMP-CRE) was measured by the self-creativity scale developed by Kaufman (2012). The employee creativity scale consists of nine items, and higher item scores indicate a higher level of creativity. 
Task performance (TASK-PERF) was measured by adopting the scale developed by Goodman and Svyantek (1999). This scale includes nine items, and high item scores represent high task performance. All scales had good internal consistency (see Table 3).

The following features of the respondents were used as control variables: age (AGE), education (EDU), sector (SECT), corporation type (CORP), and marital status (MAR).

\section{Procedure and Analysis}

Data was gathered through an online survey, and the link was sent to workers in the private sector and the public sector, as well as self-employed workers. Participants were informed about the purpose, scope, and research procedures of the study. After informed consent, participants shared their demographic information and answered survey items related to personal accomplishments, creativity, and task performance.

For data analysis, we used PLS-SEM. PLS-SEM is a variance-based structural equation modeling technique that is widely applied in business, economy, psychology, and other social sciences disciplines (Ringle \& Sarstedt, 2016). This is a structural equation model that employs a formative and reflective component-based approach for estimation purposes (Hair et al., 2019). Sample size and residual distributions are not restrictive in PLS-SEM (Chin et al., 2003). PLS-SEM is preferred by researchers because of its flexibility in normality assumption, provision of credible results with small sample sizes and complex models, theory testing from a predictive perspective, and good mediation analysis dependent on the bootstrapping method (Hair et al., 2017). PLS-SEM has no universal goodness of fit indexes, and model quality in PLSSEM depends on the ability to predict endogenous structures, the $R^{2}$ values of endogenous constructs, cross-validated redundancy $\left(\mathrm{Q}^{2}\right)$, prediction errors, relevance of path coefficients, and effect sizes $\left(\mathrm{f}^{2}\right)$.

The WarpPLS 7.0 software package program was used to evaluate the measurement model and hypothesized relationships. For the analysis procedure, we adopted Peng and Lai's (2012) two-stage model evaluation guidelines, first evaluating the measurement model and then testing the structural model. For multi-group analysis, we chose the pooled standard error method for multi-group moderation (PLS-MG) to evaluate the presence of a large number of variables and the formative factors and moderating effects of gender (Kock, 2014).

\section{Results}

\section{Measurement Model}

In the first phase of measurement model evaluation, item loadings were checked. Hair et al. (2019) highlighted that item loadings of the variables should be 0.70 and above because it ensures that the structure explains more than $50 \%$ of the factor variance. In line with this principle, noncompliant indicators were removed from the analysis. Thus, in Table 2, it may be seen that all item loadings were greater than the lower limit of 0.70 , indicating the establishment of the discriminant validity of the model.

In the second phase, the internal consistency reliability of the model was evaluated. The Cronbach's alpha (CA) value is considered a conservative measure of reliability, and the composite reliability (CR) value is regarded as a more liberal estimate. Both CA and CR values are expected to be above 0.70 for a satisfactory level of construct reliability (Hair et al., 2019). In Table 2, it may be seen that the CA and $\mathrm{CR}$ values for all three models, including the full model, the male model, and the female model, were above 0.70 , indicating significant construct reliability.

In the third phase, the convergent validity of the model was evaluated through the average variance extracted (AVE) value. The AVE values of constructs should be greater than 0.50 for a satisfactory convergent validity (Hair et al., 2019). In Table 2, it may be seen that the minimum AVE value of the full model was 0.66 , confirming the convergent validity of the constructs.

In the final phase, the discriminant validity of the model was assessed through the Fornell-Larcker criterion (Fornell \& Larcker, 1981). Regarding this criterion, the square roots of the AVE value of each variable should be greater than the correlation values of this variable with other variables (Gefen \& Straub, 2005). As shown in Table 3, the square roots of AVEs (given in diagonal) were greater than the correlation values. Thereby, the discriminant validity was confirmed according to the Fornell-Larcker criterion.

\section{Structural Model Assessment}

Structural model testing includes checking collinearity among the model constructs, examining the significance of path coefficients, performing bootstrapping for path analysis, and evaluating the predictive power and quality of the model according to certain criteria (Hair et al., 2019).

Multicollinearity problem refers to the high correlation among variables. To evaluate collinearity among the variables, Hair et al. (2019) recommend focusing on the VIF values of the constructs. Accordingly, the ideal VIF values should be less than 5 (Hair et al., 2011). As shown in Table 3, all VIF values were less than 5, indicating no collinearity problem in our study.

In the next step, the bootstrapping procedure was performed with 1000 bootstrapping subsamples to test the statistical significance of paths. Also, a bootstrapping procedure at a 5\% significance level with 1000 bootstrapping subsamples was run to test the impact of control variables 
Table 2 Item loadings, statistical reliability, and convergent validity of groups

\begin{tabular}{|c|c|c|c|c|c|c|c|c|c|}
\hline \multirow[t]{2}{*}{ Variables } & \multicolumn{3}{|l|}{ Full model } & \multicolumn{3}{|l|}{ Male } & \multicolumn{3}{|l|}{ Female } \\
\hline & PER-ACC & EMP-CRE & TASK-PERF & PER-ACC & EMP-CRE & TASK-PERF & PER-ACC & EMP-CRE & TASK-PERF \\
\hline PER-ACC 4 & 0.810 & & & 0.804 & & & 0.819 & & \\
\hline PER-ACC 5 & 0.811 & & & 0.867 & & & 0.756 & & \\
\hline PER-ACC 6 & 0.828 & & & 0.851 & & & 0.809 & & \\
\hline PER-ACC 7 & 0.802 & & & 0.824 & & & 0.788 & & \\
\hline PER-ACC 8 & 0.810 & & & 0.790 & & & 0.824 & & \\
\hline EMP-CRE 1 & & 0.849 & & & 0.821 & & & 0.853 & \\
\hline EMP-CRE 2 & & 0.882 & & & 0.895 & & & 0.864 & \\
\hline EMP-CRE 6 & & 0.932 & & & 0.898 & & & 0.932 & \\
\hline EMP-CRE 7 & & 0.924 & & & 0.930 & & & 0.913 & \\
\hline EMP-CRE 8 & & 0.901 & & & 0.887 & & & 0.898 & \\
\hline TASK-PERF 2 & & & 0.895 & & & 0.923 & & & 0.882 \\
\hline TASK-PERF 3 & & & 0.954 & & & 0.936 & & & 0.965 \\
\hline TASK-PERF 4 & & & 0.937 & & & 0.928 & & & 0.943 \\
\hline TASK-PERF 6 & & & 0.836 & & & 0.821 & & & 0.846 \\
\hline TASK-PERF 7 & & & 0.897 & & & 0.896 & & & 0.899 \\
\hline TASK-PERF 8 & & & 0.939 & & & 0.911 & & & 0.956 \\
\hline TASK-PERF 9 & & & 0.924 & & & 0.885 & & & 0.950 \\
\hline AVE & 0.660 & 0.807 & 0.833 & 0.685 & 0.786 & 0.811 & 0.639 & 0.797 & 0.848 \\
\hline CR & 0.907 & 0.954 & 0.972 & 0.916 & 0.948 & 0.968 & 0.899 & 0.952 & 0.975 \\
\hline $\mathrm{CA}$ & 0.871 & 0.940 & 0.966 & 0.885 & 0.932 & 0.961 & 0.859 & 0.936 & 0.970 \\
\hline
\end{tabular}

AVE: Average variance extracted, CR: Composite reliability, CA: Cronbach's alpha

Table 3 Descriptive statistics

\begin{tabular}{|c|c|c|c|c|c|c|c|c|c|c|c|}
\hline & Mean & SD & VIF & 1 & 2 & 3 & 4 & 5 & 6 & 7 & 8 \\
\hline 1. PER-ACC & $3.63(\mathrm{M}) 3.46(\mathrm{~F})$ & $\begin{array}{l}0.97(\mathrm{M}) \\
0.86(\mathrm{~F})\end{array}$ & 3.242 & 0.812 & & & & & & & \\
\hline 2. EMP-CRE & $3.53(\mathrm{M}) 3.53(\mathrm{~F})$ & $\begin{array}{l}1.06(\mathrm{M}) \\
1.01(\mathrm{~F})\end{array}$ & 2.708 & $0.720 * *$ & 0.898 & & & & & & \\
\hline 3. TASK-PERF & $3.92(\mathrm{M}) 3.83(\mathrm{~F})$ & $\begin{array}{l}1.04(\mathrm{M}) \\
1.15(\mathrm{~F})\end{array}$ & 3.547 & $0.795 * *$ & $0.767 * *$ & 0.913 & & & & & \\
\hline 4. AGE & $3.54(\mathrm{M}) 3.70(\mathrm{~F})$ & $\begin{array}{l}1.18(\mathrm{M}) \\
1.00(\mathrm{~F})\end{array}$ & 1.131 & $0.166^{*}$ & 0.047 & 0.112 & - & & & & \\
\hline 5. EDU & $3.53(\mathrm{M}) 3.96(\mathrm{~F})$ & $\begin{array}{l}1.28(\mathrm{M}) \\
1.11(\mathrm{~F})\end{array}$ & 1.050 & -0.030 & 0.077 & 0.068 & 0.020 & - & & & \\
\hline 6. SECT & $4.18(\mathrm{M}) 3.26(\mathrm{~F})$ & $\begin{array}{l}1.78(\mathrm{M}) \\
1.38(\mathrm{~F})\end{array}$ & 1.072 & $0.137 *$ & 0.083 & 0.050 & 0.078 & -0.101 & - & & \\
\hline 7. CORP & $1.50(\mathrm{M}) 1.47(\mathrm{~F})$ & $0.724(\mathrm{M}) 0.741(\mathrm{~F})$ & 1.074 & 0.056 & -0.056 & -0.048 & -0.001 & -0.129 & 0.143 & - & \\
\hline 8. MAR & $1.81(\mathrm{M}) 1.65(\mathrm{~F})$ & $\begin{array}{l}0.39(\mathrm{M}) \\
0.48(\mathrm{~F})\end{array}$ & 1.116 & -0.025 & -0.005 & 0.012 & $0.269 * *$ & 0.029 & 0.107 & -0.110 & - \\
\hline
\end{tabular}

Square roots of average variances extracted (AVEs) shown on diagonal

${ }^{*} p<0.05 ; * * p<0.01$

on task performance with the full model, the male participants' model, and the female participants' model. As shown in Table 4, none of the control variables was found significant in the full model (see Table 4).
Figure 2 summarizes the results of the PLS-SEM analysis, and Table 4 shows a summary of direct and indirect effects. As may be seen in both Table 4 and Fig. 2, personal accomplishment had a positive and significant effect 
on employee creativity $\left(\beta=0.720, \mathrm{f}^{2}=0.519, p<0.01\right)$ and task performance $\left(\beta=0.528, \mathrm{f}^{2}=0.420, p<0.01\right)$, thereby supporting $\mathrm{H} 1$ and $\mathrm{H} 3$, respectively. Also, employee creativity had a positive and significant effect on task performance $\left(\beta=0.385, \mathrm{f}^{2}=0.295, p<0.01\right)$, confirming $\mathrm{H} 2$. Finally, the indirect effect $\left(\beta_{\mathrm{Med}}=0.277, \mathrm{f}^{2}=0.220\right.$, $p<0.01)$ indicated that employee creativity positively mediates the relationship between personal accomplishment and task performance, providing support for $\mathrm{H} 4$.

The effect size, known as Cohen's $\mathrm{f}^{2}$, refers to the change in the $R^{2}$ value if the relevant structural variable is removed from the model. In other words, the effect size is used to evaluate the actual effect of an independent variable on the dependent variable (Hair et al., 2014; Sarstedt et al., 2019). The $\mathrm{f}^{2}$ values vary from 0.15 to $0.20,0.20$ to 0.35 , and larger than 0.35 , representing weak, medium, and strong effect sizes, respectively (Cohen, 1988). In Table 5, the effect sizes of the relationships at the full model and gender-segregated models range from 0.160 to 0.552 (medium to strong).

As is known, the PLS-SEM aims to maximize the explained total variance of the latent variables in the inner model (Hair et al., 2017). $\mathrm{R}^{2}$ values are used to understand the predictive power of the model. In other words, $\mathrm{R}^{2}$ is known as the combined effect of exogenous variables on endogenous variables, and $R^{2}$ values range from 0 to 1 (Hair et al., 2019). The acceptable $\mathrm{R}^{2}$ values depend on the research constructs and research context. Hair et al. (2014) recommended $\mathrm{R}^{2}$ values of $0.25,0.50$, and 0.75 for the endogenous constructs are weak, medium, and high, respectively. In Table 4, the full model explains $51.7 \%$ of the variance for creativity and $71.2 \%$ of the variance for task performance. These $\mathrm{R}^{2}$ values show moderate to strong predictive power (Hair et al., 2014).

$\mathrm{Q}^{2}$ is known as a predictive relevance value and is used for evaluating the predictive fit of the inner model (Chin,
Table 4 Evaluation of the structural model

Fig. 2 Structural model with PLS path coefficients. ${ }^{*} \mathrm{p}<0.05$; $* * \mathrm{p}<0.01$

\begin{tabular}{|c|c|c|c|c|c|c|}
\hline & \multicolumn{2}{|c|}{ Full model } & \multicolumn{2}{|l|}{ Male } & \multicolumn{2}{|l|}{ Female } \\
\hline & $\beta$ & $t$-value & $\beta$ & $t$-value & $\beta$ & $t$-value \\
\hline \multicolumn{7}{|l|}{ Path relationships } \\
\hline PER-ACC $\rightarrow$ EMP-CRE & $0.720 * *$ & 16.615 & $0.702 * *$ & 8.628 & $0.743 * *$ & 17.883 \\
\hline PER-ACC $\rightarrow$ TASK-PERF & $0.528 * *$ & 7.794 & $0.665 * *$ & 6.553 & $0.424 * *$ & 4.575 \\
\hline EMP-CRE $\rightarrow$ TASK-PERF & $0.385 * *$ & 6.067 & $0.227 * *$ & 2.491 & $0.496 * *$ & 5.269 \\
\hline $\begin{array}{l}\text { PER-ACC X EMP- } \\
\text { CRE } \rightarrow \text { TASK-PERF }\end{array}$ & $0.277 * *$ & 5.732 & $0.159 * *$ & 2.383 & $0.369 * *$ & 5.049 \\
\hline \multicolumn{7}{|l|}{ Control variables } \\
\hline AGE $\rightarrow$ TASK-PERF & 0.002 & 0.051 & 0.070 & 0.951 & -0.042 & -1.128 \\
\hline EDU $\rightarrow$ TASK-PERF & 0.043 & 1.317 & 0.065 & 1.200 & 0.052 & 1.147 \\
\hline $\mathrm{SECT} \rightarrow$ TASK-PERF & -0.047 & -1.475 & -0.035 & -0.650 & -0.062 & -1.654 \\
\hline $\mathrm{CORP} \rightarrow$ TASK-PERF & -0.041 & -1.098 & -0.051 & -0.829 & -0.030 & -0.804 \\
\hline MAR $\rightarrow$ TASK-PERF & 0.025 & 0.933 & 0.010 & 0.165 & 0.030 & 0.791 \\
\hline$R^{2}$ and $Q^{2}$ & $R^{2}$ & $Q^{2}$ & $R^{2}$ & $Q^{2}$ & $R^{2}$ & $Q^{2}$ \\
\hline EMP-CRE & 0.517 & 0.519 & 0.490 & 0.494 & 0.549 & 0.552 \\
\hline TASK-PERF & 0.712 & 0.720 & 0.710 & 0.729 & 0.732 & 0.746 \\
\hline
\end{tabular}

$* p<0.05, * * p<0.01$

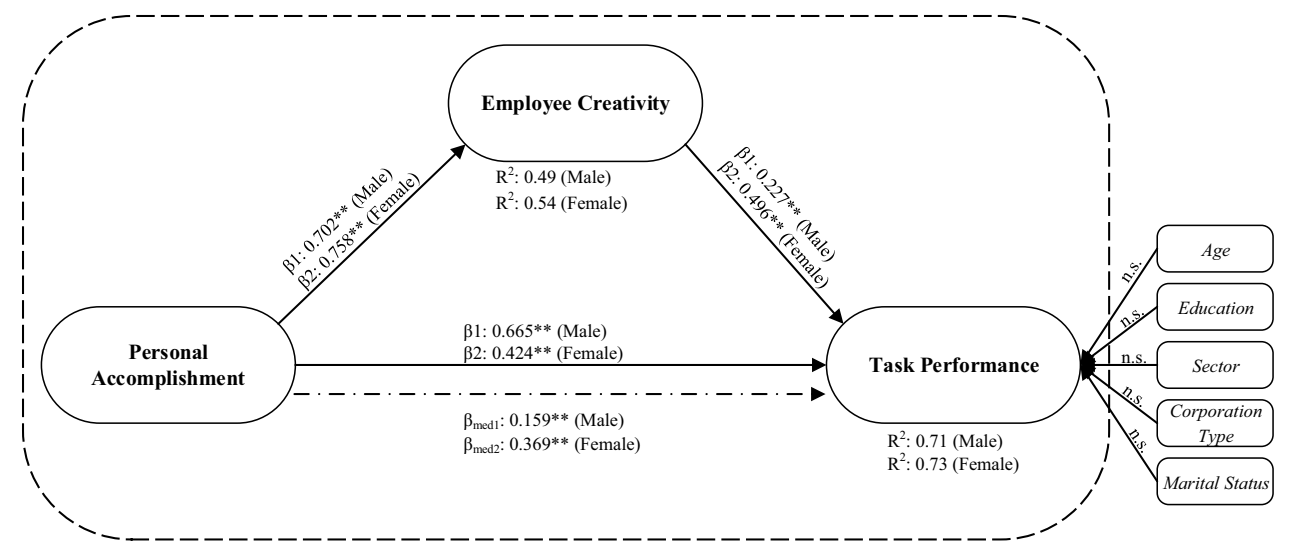


Table 5 Effect sizes $\left(\mathrm{f}^{2}\right)$ of relationships

\begin{tabular}{llll}
\hline & Full Model & Male & Female \\
\hline Path relationships & & & \\
PER-ACC $\rightarrow$ EMP-CRE & 0.519 & 0.493 & 0.552 \\
PER-ACC $\rightarrow$ TASK-PERF & 0.420 & 0.549 & 0.332 \\
EMP-CRE $\rightarrow$ TASK-PERF & 0.295 & 0.160 & 0.403 \\
Control variables & & & \\
AGE $\rightarrow$ TASK-PERF & 0.000 & 0.015 & 0.002 \\
EDU $\rightarrow$ TASK-PERF & 0.003 & 0.004 & 0.004 \\
SECT $\rightarrow$ TASK-PERF & 0.002 & 0.006 & 0.004 \\
CORP $\rightarrow$ TASK-PERF & 0.002 & 0.002 & 0.002 \\
MAR $\rightarrow$ TASK-PERF & 0.000 & 0.001 & 0.001 \\
\hline
\end{tabular}

2010). This measurement is based on the sampling reuse technique and estimates the model parameters by ignoring some part of the data matrix and attempts to predict the ignored parts by using estimates (Kock, 2018; Hair et al., 2014). The smaller the difference between the predicted and original values, the greater the $\mathrm{Q}^{2}$ and therefore the predictive accuracy of the model. An acceptable $\mathrm{Q}^{2}$ value must be greater than zero (Kock, 2018; Hair et al., 2014). In this study, Table 4 shows that $\mathrm{Q}^{2}$ values of creativity and task performance in the full model are 0.519 and 0.720 , respectively, indicating adequate predictive relevance.

\section{Multi-Group Analysis}

The multi-group analysis (MGA) in PLS-SEM aims at testing predefined data groups to understand differences in the parameter estimates among groups (Hernández-Perlines, 2016). Using MGA, researchers can understand the differences between two identical models belonging to different groups. This classification is based on parametric or nonparametric applications. In this study, PLS-MGA was performed with the pooled standard error approach in WarpPLS 6.0 (Kock, 2017) to compare female and male participants according to the hypothesized relationships in the model.

In this section, male and female models were run in order to examine the moderating effect of gender on direct and indirect relationships. The path coefficients of male and female models are given in Fig. 2, and the MGA results are presented in Table 6 by comparing male and female participants. As shown in Table 6, no support was found for $\mathrm{H} 5 \mathrm{a}$, as there is no significant variation between male and female participants for the path running from personal accomplishment to creativity. Therefore, gender does not make a significant difference in the relationship between personal accomplishment and creativity.

On the other hand, findings in Fig. 2 and Table 6 reveal significant variations between male and female participants for the paths running from personal accomplishment to task
Table 6 Multi-group analysis results

Absolute difference Standard error

\begin{tabular}{lll}
\hline Path relationships & & \\
$\mathrm{PER}-\mathrm{ACC} \rightarrow$ EMP-CRE & 0.040 & 0.087 \\
$\mathrm{PER}-\mathrm{ACC} \rightarrow$ TASK-PERF & $0.241^{*}$ & 0.122 \\
EMP-CRE $\rightarrow$ TASK-PERF & $0.270^{*}$ & 0.118 \\
PER-ACC x EMP- & $0.210^{*}$ & 0.111 \\
$\mathrm{CRE} \rightarrow$ TASK-PERF & & \\
Control variables & & \\
$\mathrm{AGE} \rightarrow$ TASK-PERF & 0.112 & 0.079 \\
$\mathrm{EDU} \rightarrow$ TASK-PERF & 0.013 & 0.066 \\
$\mathrm{SECT} \rightarrow$ TASK-PERF & 0.027 & 0.066 \\
$\mathrm{CORP} \rightarrow$ TASK-PERF & 0.021 & 0.079 \\
$\mathrm{MAR} \rightarrow$ TASK-PERF & 0.021 & 0.060 \\
\hline
\end{tabular}

$* p<0.05$

performance, creativity to task performance, and personal accomplishment to task performance through creativity, providing support for $\mathrm{H} 5 \mathrm{~b}, \mathrm{H} 5 \mathrm{c}$, and $\mathrm{H} 5 \mathrm{~d}$. The impact of personal accomplishment on task performance was more significant for male participants, the impact of creativity on task performance was more significant for female participants, and the mediating role of creativity on the relationship between personal accomplishment and creativity was more significant for female participants.

\section{Discussion}

The present study aimed to examine the mediating role of creativity on the association between personal accomplishment and task performance based on the data collected from various job groups in the COVID-19 pandemic. This study also sought to investigate the role of gender on the proposed relationships through an MGA with PLS-SEM. Finally, we added five control variables (i.e., age, education, sector, corporation type, and marital status) to the model to increase the accuracy of the results and address the issue of endogeneity (Hult et al., 2018).

Prior to testing the mediation model, preliminary analyses revealed that the sense of personal accomplishment had a significant effect on creativity and task performance. Also, it was shown that there was a positive and significant relationship between creativity and task performance. These findings are also consistent with those of previous studies. The COVID-19 pandemic is an extraordinary crisis, and in such crises, people go out of their routine, and their normal patterns change (Tang et al., 2021). In such crisis periods, they need to be more confident in order to be more successful, which increases their sense of personal accomplishment and at the same time, develops their creativity (Tang et al., 
2021). Therefore, in line with previous studies, it was found a positive and significant relationship between personal accomplishment and creativity (Ghonsooly, 2012; Hsu et al., 2011; Landeche, 2009); personal accomplishment and task performance (Fogarty et al., 2000; Vinchur et al., 1998); creativity and task performance (Eschleman et al., 2014; Janssen \& Giebels, 2013; Taboli \& Zaerizadeh, 2016).

Results of the structural model analysis revealed that creativity had a significant mediating effect on the relationship between personal accomplishment and task performance in the context of the COVID-19 pandemic. According to Hon and Lui (2016), creativity is vital in developing new ideas and producing novel solutions for problems people face in the work environment. Consistent with this mediating effect, previous researchers indicated that creative employees could contribute significantly to individual performance and business performance with innovative ideas and solutions, especially in unexpected crises and the processes of sudden change and transformation (Kanbur \& Özyer, 2016; Zhou et al., 2012). Therefore, in a severe health crisis such as the COVID-19 pandemic, the feeling of personal accomplishment positively reflects on individual creativity, which, in turn, positively affects task performance.

Remarkably, MGA results indicated that personal accomplishment-task performance linkage, creativity-task performance linkage, and personal accomplishment-task performance linkage through creativity were found statistically different between male and female employees. In previous studies, it was shown that gender plays a crucial differentiating role in issues such as personal success, performance outcomes, satisfaction, motivation, burnout, and creativity both in the workplace and outside of the workplace (Afolabi et al., 2010; Jamaludin \& You, 2019; Karwowski et al., 2013; Nasir et al., 2011). The gender effect on the personal accomplishment-task performance relationship was stronger for the male group. Consistent with the extant literature, the masculine characters of men make the feeling of success and the effort of high job performance more dominant in men (Jamaludin \& You, 2019; Kacmar et al., 2011; Nasir et al., 2011). On the other hand, the role of creativity on task performance and the mediating role of creativity on the personal accomplishment and task performance relationship was stronger for the female group. This finding was somewhat contrary to the common view in the literature. According to Baer and Kaufman (2008), males are taking higher risks, curious to try new things, and open to creative changes. Therefore, males are considered more creative in performing their tasks (Kacmar et al., 2011; Smith et al., 2016). However, the findings of this study revealed that the creativity-task performance relationship is stronger in females. Similarly, in females, creativity has a stronger mediator effect on the relationship between personal accomplishment and task performance. This has contributed significantly to the literature that females are better at transforming their creativity into task performance in times of crisis, like the COVID-19 pandemic.

\section{Conclusion}

This study is one of the pioneering studies examining the mediating effect of creativity in the relationship between personal accomplishment and task performance in the context of the COVID-19 pandemic. In addition, a genderbased group comparison was made to understand the differences between male and female participants. According to the results, while there was no significant difference in the effect of personal accomplishment on creativity in males and females, its effect on task performance was stronger in males. In addition, the effect of creativity on task performance and its mediator effect was stronger in the females' group. Finally, it should be noted that none of the control variables (age, education, sector, corporation type, and marital status) was found significant.

\section{Implications}

Drawing essentially on social cognitive theory and selfefficacy theory, this study revealed that personal accomplishment and creativity have a significant effect on task performance in pandemic conditions and that creativity is an important mediator influencing the relationship between personal accomplishment and task performance. In addition, based on social role theory and gender role theory, the effect of gender on hypothesized relationships has been revealed, considering that the difference in gender roles of females and males in the social environment can also be reflected in their roles in the business environment and the way they do business. As predicted, males' masculine character, high sense of achievement, strong desire for promotion (Kacmar et al., 2011; King et al., 2010) made the relationship between personal accomplishment and task performance stronger in the male group. However, contrary to the argument in the literature that males can be more creative than females because they like risk-taking and are more open to changes and innovations (Baer \& Kaufman, 2008; Smith et al., 2016). In this study, the effect of creativity on task performance and its mediator effect was found stronger in the female group. Therefore, it has been understood that females can better transfer their creativity to performance in times of extraordinary crisis such as the pandemic, thus making a further contribution to the field.

From a practical perspective, we have arrived at a situation where houses become the safest places and being outside loses its attractiveness. Each pandemic opens new horizons and gives way to new life habits. Due to the COVID-19 
pandemic, we are experiencing emotions such as anxiety, fear, and panic. Economic difficulties, social distance, and quarantine practices are shifting attitudes from uncertainty to hopelessness and burnout. But the inherent creativity of humans can turn this difficult period into an opportunity.

Our results suggested that managers should attach importance to the personal accomplishment and creativity of employees during the COVID-19 pandemic. Personal accomplishment is related to people's feelings of competence and success orientation in their work (Maslach et al., 1997), and creativity has vital importance for developing rapid solutions to problems under the pressure of high uncertainty and resource scarcity of the COVID-19 pandemic (Cohen $\&$ Cromwell, 2020). While the sense of personal accomplishment supports the self-confidence and motivation of the employees, individual creativity contributes to the employees' ability to cope with stress and anxiety more easily and to the performance outcomes with innovative solutions and ideas for themselves and their companies (Halbesleben \& Buckley, 2004). If personal accomplishment and creativity are high, the task performance of employees increases. Also, managers can follow gender-specific policies related to personal accomplishment-creativity, personal accomplishment-task performance, and personal accomplishment-task performance through creativity linkages. Organizations can pay more attention to female employees because the role of creativity on task performance is found higher for females. On the other hand, if creativity is not very important for a business, if the motivation of the employees for success and fulfilling the assigned tasks is important, organizations can pay attention to male employees.

\section{Limitations and Future Directions}

Like all studies, this study has some limitations. First, due to the difficulty of conducting face-to-face surveys in the COVID-19 period, data was collected through online channels based on the convenience sampling approach. Although this sampling method is widely used in the management field, it can lead to sample bias. Even though our study used a set of demographic variables to increase the reliability of the results, we recommend repeating this research depending on a random sampling technique. Second, although our research had a sufficient sample size $(n=322)$, we suggest that future researchers increase the sample size to generalize the results. Thus, future studies can contribute to the generalizability of the findings by reaching more samples from different sectors and countries with different cultures. Third, task performance was selected as the dependent variable. We suggest that future researchers study other job attitudes at workplaces, such as job involvement, organizational commitment, and job satisfaction. Fourth, task performance was evaluated with self-reported measures. While self-reported measures are mostly preferred and valid in the management field (Wall et al., 2004), we recommend that future researchers use more objective task performance measures to enhance the reliability of outcomes. Finally, this study was designed as a cross-sectional study. Future studies can better see the long-term effects of the pandemic by doing longitudinal studies in the context of PLS-SEM.

Funding This research has not received specific support from public sector agencies, the commercial sector, or non-profit organizations.

Data Availability The datasets generated during and/or analyzed during the current study are available from the corresponding author on reasonable request.

\section{Declarations}

Ethical Approval All procedures performed in studies involving human participants were in accordance with the ethical standards of the institutional and/or national research committee and with the 1964 Helsinki declaration and its later amendments or comparable ethical standards.

Informed Consent Informed consent was obtained from all individual participants included in the study.

Conflict of Interest The authors declare that there is no conflict of interest.

\section{References}

Afolabi, O. A., Awosola, R. K., \& Omole, S. O. (2010). Influence of emotional intelligence and gender on job performance and job satisfaction among Nigerian policemen. Current Research Journal of Social Sciences, 2(3), 147-154.

Aggarwal, V. S., \& Kapoor, M. (2020). Multigroup analysis of higherorder model of knowledge variables in the context of global ventures through PLS-SEM. South Asian Journal of Business Studies, 10(1), 128-146. https://doi.org/10.1108/SAJBS-02-2020-0037

Amabile, T. M., \& Conti, R. (1999). Changes in the work environment for creativity during downsizing. Academy of Management Journal, 42(6), 630-640.

Amabile, T. M., \& Pratt, M. G. (2016). The dynamic componential model of creativity and innovation in organizations: Making progress, making meaning. Research in Organizational Behavior, 36, 157-183. https://doi.org/10.1016/j.riob.2016.10.001

Aslan, A. E. (2016). Kavram boyutunda yaratıc1lık. Türk Psikolojik Danışma ve Rehberlik Dergisi, 2(16), 15-21. https://doi.org/10. 17066/pdrd. 72200

Baer, J., \& Kaufman, J. C. (2008). Gender differences in creativity. The Journal of Creative Behavior, 42(2), 75-105.

Bandura, A. (1986). The explanatory and predictive scope of selfefficacy theory. Journal of Social and Clinical Psychology, 4(3), 359-373. https://doi.org/10.1521/jscp.1986.4.3.359

Bandura, A. (1989). Regulation of cognitive processes through perceived self-efficacy. Developmental Psychology, 25(5), 729-735. https://doi.org/10.1037/0012-1649.25.5.729

Bandura, A. (1997). Self-efficacy: The exercise of control. Freeman.

Bandura, A. (2001). Social cognitive theory: An agentic perspective. Annual Review of Psychology, 52(1), 1-26. 
Bang, H., \& Reio Jr., T. G. (2016). Examining the role of cynicism in the relationships between burnout and employee behavior. Revista de Psicología del Trabajo y de las Organizaciones, 33(3), 217227. https://doi.org/10.1016/j.rpto.2017.07.002

Baysal, A. (1995). Lise ve Dengi Okul Öğretmenlerinde Meslekte Tükenmişliğe Etki Eden Faktörler. Yayınlanmamış Doktora Tezi, Dokuz Eylül Üniversitesi Sosyal Bilimler Enstitüsü, İzmir.

Bell, B. S., \& Kozlowski, W. J. (2002). Goal orientation and ability: Interactive effects on self-efficacy, performance, and knowledge. Journal of Applied Psychology, 87(3), 497. https://doi.org/10. 1037/0021-9010.87.3.497

Burleson, B. R., \& Samter, W. (1992). Are there gender differences in the relationship between academic performance and social behavior? Human Communication Research, 19(1), 155-175. https:// doi.org/10.1111/j.1468-2958.1992.tb00298.x

Chin, W. W. (2010). How to write up and report PLS analyses. In handbook of partial least squares (pp. 655-690). Springer.

Chin, W. W., Marcolin, B. L., \& Newsted, P. R. (2003). A partial least squares latent variable modelling approach for measuring interaction effects: Results from a Monte Carlo simulation study and an electronic-mail emotion/adoption study. Information Systems Research, 14(2), 189-217. https://doi.org/10.1287/isre.14.2.189. 16018

Choi, J. N., Anderson, T. A., \& Veillette, A. (2009). Contextual inhibitors of employee creativity in organizations: The insulating role of creative ability. Group \& Organization Management, 34(3), 330-357. https://doi.org/10.1177/1059601108329811

Cohen, J. (1988). Statistical power analysis for the behavioral sciences (2nd ed.). Erlbaum.

Cohen, A. K., \& Cromwell, J. R. (2020). How to respond to the COVID-19 pandemic with more creativity and innovation. Population Health Management. https://doi.org/10.1089/pop.2020. 0119

Eagly, A. H., Karau, S. J., \& Makhijani, M. G. (1995). Gender and the effectiveness of leaders: A meta-analysis. Psychological Bulletin, 117(1), 125. https://doi.org/10.1037/0033-2909.117.1.125

Ergin, C. (1992). Doktor ve hemsirelerde tukenmislik ve Maslach tukenmislik olceginin uyarlanmasi. VII. Ulusal Psikoloji Kongresi, 22nd September 1992 Ankara (Turkey).

Eschleman, K. J., Madsen, J., Alarcon, G., \& Barelka, A. (2014). Benefiting from creative activity: The positive relationships between creative activity, recovery experiences, and performance related outcomes. Journal of Occupational and Organizational Psychology, 87(3), 579-598. https://doi.org/10.1111/joop.12064

Fogarty, T. J., Singh, J., Rhoads, G. K., \& Moore, R. K. (2000). Antecedents and consequences of burnout in accounting: Beyond the role stress model. Behavioral Research in Accounting, 12, 31-68.

Fornell, C., \& Larcker, D. F. (1981). Evaluating structural equation models with unobservable variables and measurement error. Journal of Marketing Research, 18(1), 39-50. https://doi.org/10.1177/ 002224378101800104

Gates, B. (2020). Responding to Covid-19-A once-in-a-century pandemic? New England Journal of Medicine, 382(18), 1677-1679. https://doi.org/10.1056/NEJMp2003762

Gefen, D., \& Straub, D. (2005). A practical guide to factorial validity using PLS-graph: Tutorial and annotated example. Communications of the Association for Information Systems, 16(1), 91-109. https://doi.org/10.17705/1CAIS.01605

George, J. M., \& Zhou, J. (2002). Understanding when bad moods foster creativity and good ones don't: The role of context and clarity of feelings. Journal of Applied Psychology, 87(4), 687. https://doi. org/10.1037/0021-9010.87.4.687

Ghonsooly, B. (2012). Exploring the relationship between creativity and burnout among Iranian EFL teachers. International Journal of Linguistics, 4(3), 121-134. https://doi.org/10.5296/ijl.v4i3.2198
Goodman, S. A., \& Svyantek, D. J. (1999). Person-organization fit and contextual performance: Do shared values matter. Journal of Vocational Behavior, 55(2), 254-275. https://doi.org/10.1006/ jvbe.1998.1682

Hair, J.F., Hult, G.T.M., Ringle, C., \& Sarstedt, M. (2017). A primer on partial least squares structural equation modelling (PLS-SEM). Sage publications.

Hair, J. F., Ringle, C. M., \& Sarstedt, M. (2011). PLS-SEM: Indeed a silver bullet. Journal of Marketing Theory and Practice, 19(2), 139-152. https://doi.org/10.2753/MTP1069-6679190202

Hair, J. F., Risher, J. J., Sarstedt, M., \& Ringle, C. M. (2019). When to use and how to report the results of PLS-SEM. European Business Review, 31(1), 2-24. https://doi.org/10.1108/EBR-11-2018-0203

Hair, J. F., Sarstedt, M., Hopkins, L., \& Kuppelwieser, V. G. (2014). Partial least squares structural equation modelling (PLS-SEM): An emerging tool in business research. European Business Review, 26(2), 106-121. https://doi.org/10.1108/EBR-10-2013-0128

Halbesleben, J. R., \& Buckley, M. R. (2004). Burnout in organizational life. Journal of Management, 30(6), 859-879. https://doi.org/10. 1016/j.jm.2004.06.004

Hernández-Perlines, F. (2016). Entrepreneurial orientation in hotel industry: Multi-group analysis of quality certification. Journal of Business Research, 69(10), 4714-4724. https://doi.org/10.1016/j. jbusres.2016.04.019

Hon, A. H., \& Lui, S. S. (2016). Employee creativity and innovation in organizations: Review, integration, and future directions for hospitality research. International Journal of Contemporary Hospitality Management. https://doi.org/10.1108/IJCHM-09-2014-0454

Hsu, M. L. A., Hou, S. T., \& Fan, H. L. (2011). Creative self-efficacy and innovative behavior in a service setting: Optimism as a moderator. The Journal of Creative Behavior, 45(4), 258-272. https:// doi.org/10.1002/j.2162-6057.2011.tb01430.x

Hult, G. T. M., Hair Jr., J. F., Proksch, D., Sarstedt, M., Pinkwart, A., \& Ringle, C. M. (2018). Addressing endogeneity in international marketing applications of partial least squares structural equation modeling. Journal of International Marketing, 26(3), 1-21. https://doi.org/10.1509/jim.17.0151

Jamaludin, I. I., \& You, H. W. (2019). Burnout in relation to gender, teaching experience, and educational level among educators. Education Research International, 2019, 7349135. https://doi.org/10. $1155 / 2019 / 7349135$

Janssen, O., \& Giebels, E. (2013). When and why creativity-related conflict with coworkers can hamper creative employees' individual job performance. European Journal of Work and Organizational Psychology, 22(5), 574-587. https://doi.org/10.1080/1359432X. 2012.669524

Jawahar, I. M., \& Carr, D. (2007). Conscientiousness and contextual performance: The compensatory effects of perceived organizational support and leader-member exchange. Journal of Managerial Psychology, 22(4), 330-349. https://doi.org/10.1108/02683 940710745923

Kacmar, K. M., Bachrach, D. G., Harris, K. J., \& Zivnuska, S. (2011). Fostering good citizenship through ethical leadership: Exploring the moderating role of gender and organizational politics. Journal of Applied Psychology, 96(3), 633. https://doi.org/10.1037/ a0021872

Kanbur, E., \& Özyer, K. (2016). Çalışanların Bireysel Yaratıcılık Düzeylerinin İç Girişimcilik Performanslarına Etkisi. Yönetim Ve Ekonomi Araştırmaları Dergisi, 14(2), 274-265. https://doi. org/10.11611/JMER 178484

Karwowski, M., Lebuda, I., Wisniewska, E., \& Gralewski, J. (2013). Big five personality traits as the predictors of creative self-efficacy and creative personal identity: Does gender matter? The Journal of Creative Behavior, 47(3), 215-232. https://doi.org/10.1002/ jocb. 32 
Kaufman, J. C. (2012). Counting the muses: Development of the Kaufman domains of creativity scale (K-DOCS). Psychology of Aesthetics, Creativity, and the Arts, 6(4), 298. https://doi.org/10. 1037/a0029751

King, E. B., Hebl, M. R., George, J. M., \& Matusik, S. F. (2010). Understanding tokenism: Antecedents and consequences of a psychological climate of gender inequity. Journal of Management, 36(2), 482-510. https://doi.org/10.1177/0149206308328508

Kock, N. (2014). Advanced mediating effects tests, multi-group analyses, and measurement model assessments in PLS-based SEM. International Journal of e-Collaboration (IJeC), 10(1), 1-13. https://doi.org/10.4018/ijec.2014010101

Kock, N. (2017). WarpPLS user manual: Version 6.0. ScriptWarp systems: Laredo, TX, USA.

Kock, N. (2018). Should bootstrapping be used in PLS-SEM? Toward stable P-value calculation methods. Journal of applied. Structural Equation Modeling, 2(1), 1-12. https://doi.org/10.47263/JASEM. 2(1)02

Landeche, P. (2009). The correlation between creativity and burnout in public school classroom teachers. Unpublished master thesis. University of Southwest Louisiana.

Mardanov, I. (2020). Intrinsic and extrinsic motivation, organizational context, employee contentment, job satisfaction, performance and intention to stay. In Evidence-based HRM: a Global Forum for Empirical Scholarship. Emerald Publishing Limited. https://doi. org/10.1108/EBHRM-02-2020-0018.

Martínez-Monteagudo, M. C., Inglés, C. J., Granados, L., Aparisi, D., \& García-Fernández, J. M. (2019). Trait emotional intelligence profiles, burnout, anxiety, depression, and stress in secondary education teachers. Personality and Individual Differences, 142, 53-61. https://doi.org/10.1016/j.paid.2019.01.036

Maslach, C., \& Jackson, S. E. (1981). The measurement of experienced burnout. Journal of Organizational Behavior, 2(2), 99-113. https://doi.org/10.1002/job.4030020205

Maslach, C., Jackson, S.E., \& Leiter, M.P. (1997). Maslach burnout inventory. Scarecrow Education.

Miller, R. L., Griffin, M. A., \& Hart, P. M. (1999). Personality and organizational health: The role of conscientiousness. Work \& Stress, 13(1), 7-19. https://doi.org/10.1080/026783799296156

Mumford, M. D., Scott, G. M., Gaddis, B., \& Strange, J. M. (2002). Leading creative people: Orchestrating expertise and relationships. The Leadership Quarterly, 13(6), 705-750. https://doi.org/ 10.1016/S1048-9843(02)00158-3

Nasir, R., Fatimah, O., Mohammadi, M. S., Shahrazad, W. W., Khairudin, R., \& Halim, F. W. (2011). Demographic variables as moderators in the relationship between job satisfaction and task performance. Journal of Social Science and Humanities, 19, 33-40.

Pattnaik, S. C., \& Sahoo, R. (2021). Employee engagement, creativity and task performance: Role of perceived workplace autonomy. South Asian Journal of Business Studies., 10(2), 227-241. https:// doi.org/10.1108/SAJBS-11-2019-0196

Peng, D. X., \& Lai, F. (2012). Using partial least squares in operations management research: A practical guideline and summary of past research. Journal of Operations Management, 30(6), 467-480. https://doi.org/10.1016/j.jom.2012.06.002

Ouyang, K., Lam, W., \& Wang, W. (2015). Roles of gender and identification on abusive supervision and proactive behavior. Asia Pacific Journal of Management, 32(3), 671-691. https://doi.org/ 10.1007/s10490-015-9410-7

Ringle, C. M., \& Sarstedt, M. (2016). Gain more insight from your PLS-SEM results: The importance-performance map analysis. Industrial Management \& Data Systems, 116(9), 1865-1886. https://doi.org/10.1108/IMDS-10-2015-0449

Ryan, R. M., \& Deci, E. L. (2000). Intrinsic and extrinsic motivations: Classic definitions and new directions. Contemporary Educational Psychology, 25(1), 54-67. https://doi.org/10.1006/ceps.1999.1020
Sarstedt, M., Hair Jr., J. F., Cheah, J. H., Becker, J. M., \& Ringle, C. M. (2019). How to specify, estimate, and validate higher-order constructs in PLS-SEM. Australasian Marketing Journal, 27(3), 197-211. https://doi.org/10.1016/j.ausmj.2019.05.003

Smith, R. M., Sardeshmukh, S. R., \& Combs, G. M. (2016). Understanding gender, creativity, and entrepreneurial intentions. Education+. Training. https://doi.org/10.1108/ET-06-2015-0044

Stajkovic, A. D., \& Luthans, F. (1998). Self-efficacy and work-related performance: A meta-analysis. Psychological Bulletin, 124(2), 240. https://doi.org/10.1037/0033-2909.124.2.240

Stoltzfus, G., Nibbelink, B. L., Vredenburg, D., \& Hyrum, E. (2011). Gender, gender role, and creativity. Social Behavior and Personality: An International Journal, 39(3), 425-432. https://doi.org/10. 2224/sbp.2011.39.3.425

Swaminathan, M., \& Mishra, M. (2020). Non-monetary levers to enhance employee engagement in organizations-"GREAT" model of motivation during the COVID-19 crisis. Strategic HR Review, 19(4), 171-175. https://doi.org/10.1108/ SHR-04-2020-0028

Taboli, H., \& Zaerizadeh, M. (2016). Examine the effect of individual creativity on job performance with the mediating role of ethical leadership of headquarters staff of Hormozgan University of Medical Sciences. International business management, 10(8), 1427-1433. https://doi.org/10.36478/ibm.2016.1427.1433.

Tang, M., Hofreiter, S., Reiter-Palmon, R., Bai, X., \& Murugavel, V. (2021). Creativity as a means to well-being in times of COVID-19 pandemic: Results of a cross-cultural study. Frontiers in Psychology, 12, 265. https://doi.org/10.3389/fpsyg.2021.601389

Tu, Y., Li, D., \& Wang, H. J. (2021). COVID-19-induced layoff, survivors' COVID-19-related stress and performance in hospitality industry: The moderating role of social support. International Journal of Hospitality Management, 95, 102912. https://doi.org/ 10.1016/j.ijhm.2021.102912

Vinchur, A. J., Schippmann, J. S., Switzer III, F. S., \& Roth, P. L. (1998). A meta-analytic review of predictors of job performance for salespeople. Journal of Applied Psychology, 83(4), 586. https://doi.org/10.1037/0021-9010.83.4.586

Wall, T. D., Michie, J., Patterson, M., Wood, S. J., Sheehan, M., Clegg, C. W., \& West, M. (2004). On the validity of subjective measures of company performance. Personnel Psychology, 57(1), 95-118. https://doi.org/10.1111/j.1744-6570.2004.tb02485.x

Wright, T. A., \& Bonett, D. G. (1997). The contribution of burnout to work performance. Journal of Organizational Behavior: The International Journal of Industrial, Occupational and Organizational Psychology and Behavior, 18(5), 491-499. https://doi. org/10.1002/(SICI)1099-1379(199709)18:5<491::AID-JOB80 4>3.0.CO;2-I

Yu, C., \& Frenkel, S. J. (2013). Explaining task performance and creativity from perceived organizational support theory: Which mechanisms are more important? Journal of Organizational Behavior, 34(8), 1165-1181. https://doi.org/10.1002/job.1844

Zhou, Q., Hirst, G., \& Shipton, H. (2012). Context matters: Combined influence of participation and intellectual stimulation on the promotion focus-employee creativity relationship. Journal of Organizational Behavior, 33, 894-909. https://doi.org/10.1002/job.779

Publisher's note Springer Nature remains neutral with regard to jurisdictional claims in published maps and institutional affiliations. 